\title{
The network analysis of international relations: Overview of an emergent methodology
}

\author{
Péter Kacziba \\ Department of Political Science and International Studies, \\ University of Pécs, Hungary \\ kacziba.peter@pte.bu
}

ORCID 0000-0002-9567-5363

\begin{abstract}
The increasing complexity of international sphere and transnational processes challenge the traditional methodologies of International Relations. The growing number of state and non-state actors and the increasingly rapid interactions among them demand the development of new methodologies by which the international complexity could be more traceable and analysable. This paper reviews the framework of network paradigm among the possible alternatives. It examines the history of social network analysis, outlines core concepts of the most important pioneers and authors in IR, as well as investigates the possibilities and limits of network methodology. The aim of the paper is to briefly introduce network analyses trends that began to transform the traditional research methodologies in the field of international studies and related fields, including geopolitics and geoeconomics. The study will use two reference networks developed by the author to demonstrate methodological alternatives and explain the most important options of disciplinary application. At the end, the paper will illustrate that, despite its existing limitations, the network approach is particularly useful for studying and understanding international interactions.
\end{abstract}

Keywords: social network analysis, methodology, network approach of IR

JEL Classification: D85, F50, F59

\section{INTRODUCTION}

Network science has many definitions and interpretations. By simplifying and generalizing these, we may conclude that network science is the science of interactions. As its methodology provides a wide range of opportunities to analyse systems created by relations, it is applied in several fields from mathematics through biology to economics. The network approach has emerged in the past decades in the study of International Relations (IR) as well, which is a natural outcome concerning the fact that the discipline of IR investigates international interactions among state and non-state actors. 
The network approach applied in IR is based on the assumption that international relations are formed by complex networks of interactions in which state and non-state entities forge ties with one another. Studies applying the methodology attempt to answer the questions of how, why and when networks of international relations form; how they transform through the changes of history; and how these transformations influence individuals and communities (Maoz, 2011; Maoz, 2017; Kim, 2020). It also analyses the features of interactions taking place within or between international networks; investigates the macro and micro characteristics of systemic stability; the chains of historical events' consequences in time and space; and the causes of economic inequalities (Hafner-Burton et al., 2009; Victor et al., 2017; Kim, 2020).

Whichever of these topics are examined, the network approach of IR is mainly positivist and applies various means of mathematical measures. Though it does not analyse only social networks, its scientific evolution is closely associated with social studies, while its methodology was mainly influenced by networkrelated academics working in the fields of social anthropology, sociology and political science. Thus, before introducing the methodological alternatives, the paper first reviews the development of social network analysis and the emergence of IR's network approach. The literature review is followed by the description of methodological alternatives. This section uses sample diplomatic networks from the years of 1899 and 2015 to explain the most important options of disciplinary application. At the end, the paper concludes with the potentials and limitations, outlining that the network approach of IR is particularly useful for the analysis of international interactions, but less effective for answering qualitative questions.

\section{LITERATURE REVIEW}

\subsection{Social network analysis: The background field}

The methodologies of social and behavioural sciences began to apply network approaches from the onset of 1930s. Scott (2000), who was examining the historical development of the analysis of social networks, has divided this pioneering period into three closely related traditions:

- the sociometric tradition, which tested network approach through smaller units of analysis;

- the Harvardian group, that examined the patterns of interpersonal relations with mathematical methods;

- and the Mancunian school, which used network analysis to discover macro or micro features of social anthropology.

Besides the obvious background in natural sciences, all three traditions were actively influenced by German gestalt psychology. During the interwar period, the gestalt paradigm of psychology put a special emphasis on finding patterns of human sensation and employed a methodology that made a clear difference between individual system attributes and properties of the whole system (Wertheimer \& Puente, 2020). The concept had rediscovered the ancient Aristotelian idea of "the whole greater than the sum of its parts" and impacted research methodologies far beyond psychology.

In the following decades, this fundamental notion of gestalt psychology also had a significant impact on researchers dealing with social networks. The forerunner authors of social network analysis all assumed that interpersonal relations influence the behaviour of individuals and, thus, considered the network approach as a possible instrument for mapping social relations. Based on this theoretical background, Moreno (1934), who was examining the psychological bases of social configurations, developed the method of sociometry. The new scheme of sociometry did not only make the quantification of interpersonal relations possible but also provided an analytical framework for the comparison of structural components (Wassermann \& Faust, 1994). 
The Harvardian school supplemented these achievements with an idea of social space. Kurt Lewin, founder of the school, connected social dynamics with the environment where individuals and groups exist, and concluded that social space transforms through reciprocal interactions and systemic effects. According to Lewin, as the interactions of social groups and their environment may be described through depictable and analysable topological relations, the interdependence between them can also be examined by mathematical means (Scott, 2000). Thanks to Dorwin Cartwright and Frank Harary (1956), Fritz Heider's structural balance theory (1946) has also led to the progress of social network analysis. By rediscovering Heider's concept of emotion formations in triadic relations, Cartwright and Harary had realised that graph theory could be able to depict frameworks of relational connections and may provide analysable mathematical data. In the authors' approach, the components of group dynamics were described as points or nodes representing individuals, while their connections were depicted as lines or edges with marks plus $(+)$ and minus $(-)$, reflecting the information content of sentiments (Cartwright \& Harary, 1956).

As the method of Cartwright and Harary was mainly based on triadic relations, the Mancunian school's structural approach extended the idea and introduced a more progressive research basis. In 1954, social anthropologist John A. Barnes was the first to use the term social network, while he also pointed out that network analysis of isolated social groups may lead to the understanding of systemic properties (Barnes, 1954). Another member of the Mancunian school, J. Clyde Mitchell (1969) further elaborated Barnes's approach by examining the connection between systems and their components. By analysing the social structures in African cities, he came to the conclusion that the examined social networks can be divided into three categories. From these categories, the first conceptualizes the network as a whole, as a system; the second partitions this whole into a certain number of parts (subnetworks); while the third selects the individual components (nodes) that constitute the entire network structure. According to Mitchell (1969), these levels and units maintain close relations with each other, and besides information exchange, several additional interactions take place through the network channels (edges) such as the flow of material assets or exchange of services.

The sociometric, the Harvardian and the Mancunian schools all contributed to the development of social network analysis. By the late 1960s, the difficult challenge of understanding patterns of social relations also developed inter- and often multidisciplinary cooperations. These collaborations not only introduced new terms and methodologies to social sciences, but also created a new subfield: the field of social network analysis. In the following decades, the evolution of this subfield has continued. New terms such as clique, egocentric network, prestige or reciprocity have appeared more and more often, and slowly transformed not only social network analysis but also network science as a whole (Wassermann \& Faust, 1994).

Besides the disciplines mentioned above, the development of network approach has influenced the methodology of other fields of social sciences. Among these, the experiments in political science had the greatest impact on IR, though it cannot be doubted that certain network-related macroeconomic studies also affected the network pioneers of IR (e.g. Polacheck, 1980; Steiber, 1979). For the purpose of better understanding these influences, it is useful to divide the network approach of political science into three historical waves (Victor et al., 2017: 9). The first wave is related to the sociometric methodology established by Moreno: in the pioneering period of the 1930s, sociometric approaches were also employed to examine decision-making and legislative processes, as well as group and interpersonal relations of the political arena (e.g. Routt, 1938). The second wave is related to the behaviourist trends of the 1950s and 1960s, when network analysis studied the psychological characters of political (f)actors and tried to outline the relational attributes of political embeddedness. The focus of analysis in this era varied from the interpersonal relations of decision-makers (e.g. Patterson, 1959; Eulau, 1962; Monsma, 1966) through the importance of informal communication between politicians (e.g. Matthews, 1959; Fiellin, 1962) to the examination of voting behaviour (e.g. Lazarsfeld et al., 1968). The third wave has begun in the 1980s, and it is technically still going 
on. The beginning of this era synthesized the theoretical background and accumulated large quantities of statistical data (e.g., Correlates of War Project), while the 1990s developed new methodologies for analysing political relations and behavioural patterns through computer modelling and digital automatization. By the beginning of the 21 st century, the computer-assisted analysis of traditional political reality was supplemented with the exploration of political activities in the cyberspace. Today, besides the conventional topics of political relations and interactions, network analysis examines political activities on the internet, studies the societal impacts of social media platforms, attempts to reveal the effects of fake news or maps how Twitter one-liners influence voters. This ongoing and ever-expanding process transforms social network analysis on a remarkably wide scale, and, besides political science, provides new methodological opportunities for the discipline of IR as well.

\subsection{Network analysis trends in the international relations}

The network approach has spread to IR in the 1960s, although its impact remained to be limited for decades. While the early network methodologies of political sciences were influenced by the traditions of sociometric and sociological practices, the first researchers of international networks were inspired by the works of Kurt Lewin and the structural approach of social anthropology (e.g. Patterson, 1959; Eulau,1962; Monsma, 1966; Matthews, 1959; Fiellin, 1962; Lazarsfeld et al., 1968). Hence, the first network analyses dealing with international relations examined the structural characteristics of international sphere and investigated the systemic patterns of interactions taking place in it. Besides the processes in macroeconomy, the early period of structural analysis had examined membership distributions in international organizations, the patterns of diplomatic exchanges, and the community characteristics of alliance systems (e.g. Brams, 1966, 1969; Russett \& Lamb, 1969; Christopherson, 1976; Caporaso, 1978). For instance, Brams (1966), one of the first researchers of the structural approach, attempted to understand the quantitative frameworks of Cold War bipolarity, hence clustered states based on their organization memberships, trade relations and diplomatic partnerships. Bruce Russett, another pioneer of the field, also made efforts to delineate alternative regions clustered by similarities and differences of political systems, cultures and identities (1968, 1969). Russett's writings impacted IR's network research in two parallel ways. Firstly, he established a research model based on the assumption that relational ties, more precisely diplomatic linkages, may quantitatively reveal groups and cooperative communities. Secondly, he dropped the conventional way of randomly partitioning the sample and rather had detected inbuilt clusters based on frequency of relational ties.

Even though the results of Russett's studies were based on relatively short sampling periods, the employed methodology significantly influenced the following researches. By the 1970s, the analyses of diplomatic linkages introduced network terms such as reciprocity and prestige, while also established a theoretical background of international status hierarchy based on structural balance and diplomatic history (Healy \& Stein, 1973; McDonald \& Rosecrance, 1985). From the 1980s, clustering and community detection launched a new chart and turned towards the direction of block model analysis which tested dependence theories and revealed separate international communities based on socioeconomic aspects (e.g. White et al., 1976; Breiger, 1981; Nemeth \& Smith, 1985; Faber, 1987).

Since the 1970s, a new model began to erode the dominance of the structural approach. In this period the sociometric and politological network analysis started to deal with IR related questions and examined topics such as the elite's perceptions of foreign policy, the decision-making processes of foreign affairs or psychology characteristics of global leaders. For instance, Axelrod et al. (1976) endeavoured to create a cognitive network of political elites and expected to understand decisive concepts of foreign policy decisionmaking and political manipulation. Though this method raised more questions than it answered, it still 
pointed out that, besides analysing actual relations, network science can also map and examine latent and abstract connections.

The first period of IR's network approach — which lasted from the 1960s to the 1990s — was followed by a more productive wave beginning in the first decade of 21 st century. While the pioneering period applied network methodology for understanding the general structures and systemic patterns of international relations, the second wave focused on the role of mathematical analysis, outcome prediction and theory formation (Victor et al., 2017). The relative popularity of network paradigm in this era was the result of two parallel and closely associated processes. First, the advancement of digital technology extended storing capacities and made largescale data management easier and cheaper (Maoz, 2011). Secondly, the timeconsuming traditional data collection methodologies were replaced by automatically controlled datamining practices which allowed faster and more comprehensive depiction of global relations. In the following era, the analysis of large datasets determined the studies of international organizations, conflicts, human rights, arms trade or terrorism (Victor et al., 2017). The network analysis of these topics connected classical theoretical debates in IR with basic network concepts such as centrality, structural equivalency, transitivity and preferential attachment (Hoff \& Ward, 2004; Hafner-Burton \& Montgomery, 2006; Maoz et al., 2006; Cranmer et al., 2012). Just to mention a few outstanding examples from this era, Hafner-Burton et al. (2006) as well as Dorussen and Ward (2008) applied the network approach to analyse the liberal doctrines of international organizations and confirmed that the (conflict mitigating) efficiency of these institutions resides in their network structure providing access for frequent interactions. Corbetta and Grant (2012) examined a different research problem and returned to the structural balance theory by analysing the interventional role of third parties in dyadic conflicts. Through their extensive network analysis, the authors observed that the relations between intervening actors and conflict-affected target areas might determine the interventional willingness, influence the intervening method, and affect the neutrality of decision-making (Ibid.). While these results provided answers for mainly IR related questions, Maoz's analyses of international networks responded to multidisciplinary challenges of network science. For instance, among other topics, Maoz tested the theory of preferential attachment and came to the conclusion that the growth of trade and alliance networks tend to confirm the model of Barabási and Albert (1999) maintaining that newly emerging network links prefer hubs with the largest number of connections (Maoz, 2012b).

\section{METHODOLOGICAL ALTERNATIVES}

The network approach of IR explores and displays the relations among international actors and studies the interactions between structural levels and units. Its methodology uses the toolkits of social network analysis, although, in case of specific topics, it may also focus on different measuring alternatives. The current section of the study attempts to summarize these methodological alternatives and offers to employ an easy but sufficiently complex example for explaining the most important metrics and methods. In the following pages, the paper explains the most important methodological means by using two international network models (Figure 1 and 2) that visualize the global networks of diplomatic missions in the years of 1899 and 2015. By using these examples, the methodological section will hopefully provide a theoretical and practical framework for understanding the basics of IR's network paradigm.

\subsection{Reference networks: Samples for demonstrating the methodology}

In order to present the main methodological alternatives, the study set out to develop two relatively simple, yet sufficiently complex networks. The first reference network (Figure 1) depicts the global network of diplomatic missions in 1899, while the second (Figure 2) displays the same subject in 2015. Nodes in the sample networks represent sovereign and internationally recognised states, while links between them 
indicate the existence of diplomatic relations. The reference networks depict diplomatic relations between states, permanent missions delegated to intergovernmental organizations have not been included. The size of the nodes indicates the total number of incoming and outgoing diplomatic relations, and the position of countries in the given networks reflects their centrality in the diplomatic space. It is also important to note that the data collection has selected only the highest-ranking diplomatic missions, lower levels and consular offices have not been identified separately. Data was obtained from the Correlates of War project (Bayer, v2006.1.) in the case of Figure 1, and from the diplomatic notes of Europa World Year Book in the case of Figure 2 (Europa Publications, 2016). The visualisation of the networks was conducted by Cytoscape 3.5.1., an open-source software that also performed the basic mathematical calculations by using inbuilt algorithms.

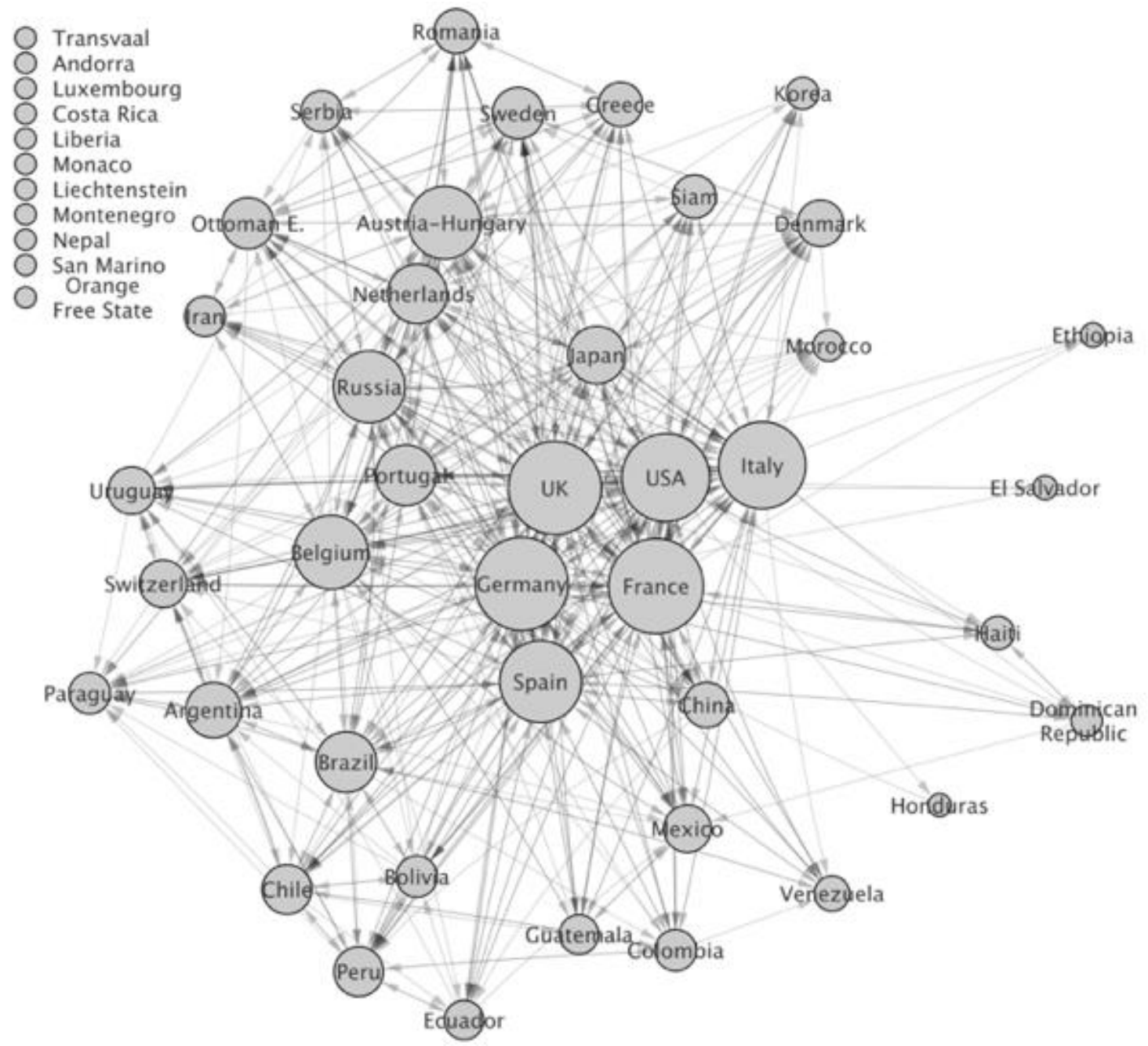

Figure 1 Global network of diplomatic missions, 1899

Source: Bayer, 2006. Edited by the author. Software: Cytoscape 3.5.1.

(Prefuse Force Directed Layout, node size defined by the number of degrees.) 


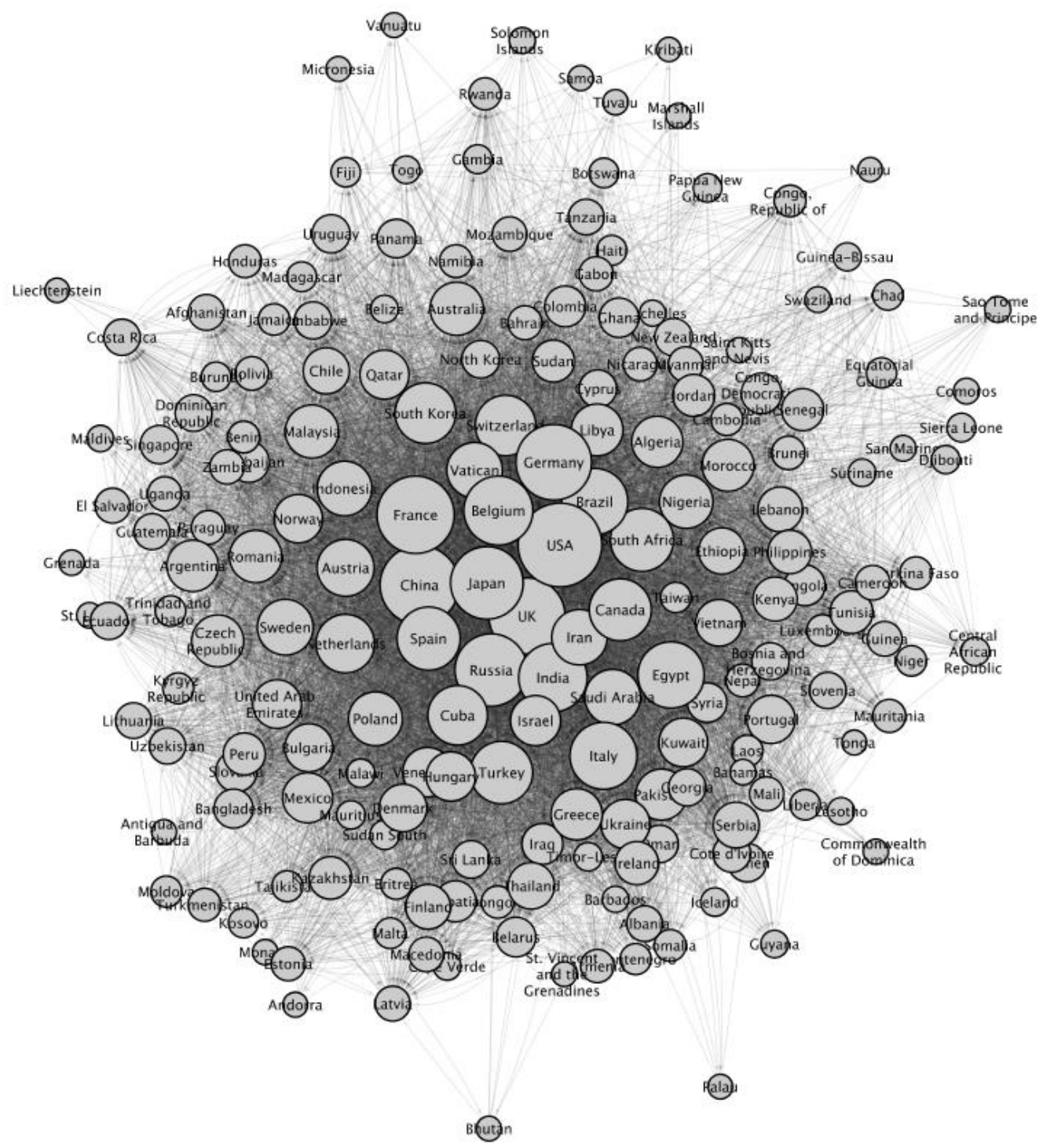

Figure 2. Global network of diplomatic missions, 2015

Source: Europa Publications, 2016. Edited by the author. Software: Cytoscape 3.5.1.

(Prefuse Force Directed Layout, node size defined by the number of degrees.)

\subsection{Methodological alternatives and properties of sample networks}

In this section, the paper will use the reference networks to unfold possible methodological options. The methodological part focuses particularly on the possibilities that are often applied by the network approach of IR. To begin with the basics, as any networks or graphs, the examples in Figure 1 and 2 also comprise two essential components, vertices and edges. Vertices or nodes $(N)$, in this case, represent states who either delegate or host diplomatic missions. Edges or links $(L)$ between $\mathrm{N}$ nodes display existing interactions. In this example, they show the existence of diplomatic links. The number of $L$ edges between $\mathrm{N}$ nodes is a variable, and it is always determined by the research sample. As Figure 1 and 2 visualize only the exchange of highest-ranking diplomatic missions (mostly embassies), in this example, $\mathrm{N}$ nodes connect to other $\mathrm{N}$ vertices with a maximum of two $\mathrm{L}$ edges, as a maximum of one hosted and one delegated representation. 
The example also illustrates the importance of edge direction. Our models display directed networks in which, contrary to the undirected relations, the direction of incoming and outgoing edges contain different information contents (Wassermann \& Faust, 1994). These information contents and the direction of edges also provide crucial background for understanding the symmetry or asymmetry of directed node-pairs and determining the reciprocity $(r)$ rate of network connections. While symmetry and asymmetry specify the quantities of mutually linked node pairs, the reciprocity provides overall data on the network's reciprocal relations (Newman, 2010). In the case of reference networks, the directed network depicted in Figure 1 contains $\mathrm{N}=52$ nodes (or states) connected by $\mathrm{L}=628$ edges (or diplomatic links). From these links, 106 connections are asymmetric (16.67\%). In the directed network depicted in Figure 2, both quantities of nodes and edges increased to $\mathrm{N}=196$ and $\mathrm{L}=9260$, while the asymmetry rate of dyadic relations (16.01\%) remained similar to the rates measured in Figure 1. Thus, the rate of reciprocity ${ }^{1}$ seems to be high in the given networks, $\mathrm{r}=0.85$ in 1899 and $\mathrm{r}=0.84$ in $2015 .{ }^{2}$ Consequently, in our sample models, the probability of finding symmetric connections seems to be high, suggesting that states tend to reciprocate the diplomatic investments of other countries.

Beyond asymmetry and symmetry, density $(D)$ also determines the topological characteristics of a given network. In this case, the existing and non-existing connections both contain important information content: the density rate compares the number of actual connections to the number of maximum possible ties; thus, it encounters how many connections have developed from the maximum potential number of network ties (Wassermann \& Faust, 1994). In the case of the referential examples, a maximum of 1326 links $\left(L_{\text {max }}\right)^{3}$ could have been formed in the year of 1899 from which 628 edges had actually evolved, meaning a $\mathrm{D}=0.47$ rate of density. In the case of $2015, \mathrm{~L}_{\max }$ provided 19110 potential links, from this possible maximum 9260 developed in reality. ${ }^{4}$ Thus, in the case Figure 2, the density rate is calculated around $\mathrm{D}=0.48$. In both cases, the statistics of density showed lower levels than the rate of reciprocities which suggests that both the existing and non-existing diplomatic ties tend to be symmetric. In other words, the probability of delegating diplomatic missions to a high number of foreign states is relatively low, however, when one side opens a diplomatic mission than the other side is likely to reciprocate it.

The difference between Figure 1 and 2 may be also characterized by the term of connectedness. While the sample from 2015 is a connected network as a path determinable in distance can be depicted from any $\mathrm{N}$ point to any other $\mathrm{N}$ point, the model from 1899 has isolated vertices (components) that are not connected parts of the network.

As other disciplines, IR may also analyse relational structures in networks as monadic, dyadic, triadic, clustered or systemic relations. In the case of a monadic unit of analysis, individual vertices are examined: the properties of individual nodes, as well as the changes in these properties, may have significant information content. In the monadic examination, the characteristics of any $\mathrm{N}$ node is described by $\mathrm{N}$ itself, its connections or by the lack of its connections (Szántó \& Tóth, 2011). The number of links connected to nodes determines the degree quantity $(k)$ of individual vertices and provide crucial information for network analysts. ${ }^{5}$ However, even in monadic relations, a difference should be made between directed and undirected

\footnotetext{
${ }^{1}$ One of the most traditional ways to determine reciprocity is to use the equation $r=\frac{L^{\leftrightarrow}}{L}$, where $L \stackrel{\leftrightarrow}{\text { is }}$ the sum of symmetric nodepairs and $L$ is the total number of edges in the network.

${ }^{2}$ Reciprocity range $0 \leq \mathrm{r} \leq 1$.

${ }^{3}$ The mathematical formula for calculating maximum possible edges in a given directed network is defined as $L_{\max }=\frac{N(N-1)}{2}$.

${ }^{4}$ In mathematical forms, density is calculated by $D=\frac{L}{L_{\max }}$.

5 The $\mathrm{k}$ degree of $\mathrm{N}_{\mathrm{i}}$ node is the sum of edges connected to the $\mathrm{N}_{\mathrm{i}}$. In directed networks, a distinction should be made between incoming and outgoing edges, the sum of which determines the total number of degrees: $k_{i}^{\text {total }}=k_{i}^{\text {in }}+k_{i}^{\text {out }}$.
} 
networks, as directed edges produce incoming $\left(k_{t}^{i n}\right)$ and outgoing $\left(k_{t}^{o u t}\right)$ ties with different data contents. The unconnected $\mathrm{N}$ point with $\mathrm{k}=0$ degree ${ }^{6}$ is an isolated part of the network, it serves as a separate component compared to the connected subnetwork(s).

One of the most frequently analysed network units is the dyad relation. In the case of a dyadic connection, the binary link between any $\mathrm{N}$ point and another $\mathrm{N}$ point is examined. The methodological literature lists four possible ways of such dyadic interactions:

- An analysed dyad is connected on 0th degree if there is no link between the two points;

- it is connected on the 1 st degree if its points are connected with an undirected link;

- it is connected on the 2 nd degree if a directed link in one direction connects the selected nodes;

- and it is connected on the $3 \mathrm{rd}$ degree if directed links are reciprocal (Ibid.).

Besides the presence or absence of various types of connections, the links may be also differentiated by weight $(A)$. While all links must have equal importance in unweighted networks, the links have individually assigned weights and thus different importance in weighted networks. As the examples of Figure 1 and Figure 2 display unweighted networks, in these cases, all edges have the same $A_{i j}=1$ weight. The determination of edge weight is again defined by the particular research sample or the researcher. Consequently, unweighted networks could be transformed into weighted networks by changing the focus of analysis. In our references, for instance, adding the number of diplomats working in diplomatic missions would be a viable option for assigning weights.

The next unit of structure analysis is the triadic level, examining the relation of three network nodes. Besides analysing features mentioned already in monadic and dyadic relations, the measuring of structural balance is the most common alternative in the study of triad connections (Wassermann \& Faust, 1994). Structural balance is particularly crucial for IR's realist perspective as the context of "the enemy of my enemy is my friend" often provides examples for studying triadic relations. The notion of structural balance assigns marks to edges and, in the most basic model, illustrates possible configurations of positive and negative relationships and outcomes. Taking a random example from our diplomatic samples: in an undirected triadic relation between the Poland $\left(N_{1}\right)$, Hungary $\left(N_{2}\right)$ and Czechia $\left(N_{3}\right)$, counting the positive and the negative options, four balanced and four unbalanced relations may be formed (Figure 3).
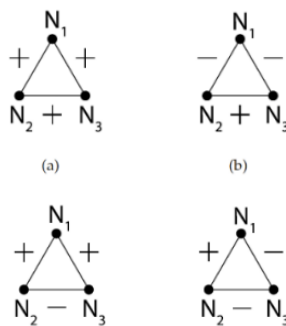

(e)

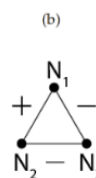

(f)

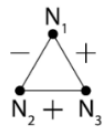

(c)

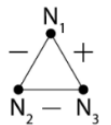

(g)

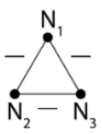

(d)

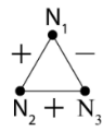

(h)

Figure 3. Possible configurations in an undirected and signed $(+,-)$ network $^{7}$

Source: Corbetta \& Grant 2012; Newman, 2010. Edited by the author.

\footnotetext{
${ }^{6}$ In case of directed networks: $\mathrm{k}_{\text {in }}=0, \mathrm{k}_{\text {out }}=0$.

${ }_{7}$ The relation is balanced, if $\mathrm{N}_{1}, \mathrm{~N}_{2}$ and $\mathrm{N}_{3}$ are in a mutually positive relation to each other (a), or if the positive relation of $\mathrm{N}_{2}$ and $\mathrm{N}_{3}$ is completed in a mutually negative relation towards $\mathrm{N}_{1}$ (b). The connection is also balanced in the case of other variants of (b), namely in (f) and (g). Unbalanced relation is formed when the connection between $\mathrm{N}_{2}$ and $\mathrm{N}_{3}$, or between $\mathrm{N}_{3}$ and $\mathrm{N}_{1}$ is positive, but the relation of $\mathrm{N}_{1}$ and $\mathrm{N}_{2}$ is negative (c). This is also the case when all connections are negative (d). In the case of (c), the negative relation of $\mathrm{N}_{1}$ and $\mathrm{N}_{2}$ cause inconsistency in the relation between $\mathrm{N}_{1}$ and $\mathrm{N}_{2}$, as well as between $\mathrm{N}_{2}$ and $\mathrm{N}_{3}$; while in the case of (d), the variation of "my enemy's enemy is also my enemy" comes into effect, which makes the relation unbalanced (Newman, 2010). In this case, (e) and (h) are the variants of (c), so both results in unbalanced connections. It is clear when examining the eight triad connections that balanced relations are formed in the case of 0 or even number of negative links (Corbetta \& Grant 2012 ; Newman, 2010).
} 
The analysis of structural balance provides at least two methodological prospects. The first one is outcome prediction: possible relational scenarios in triadic relations may all be listed and examined with the help of structural balance theory. Secondly, balanced networks with signed links may also be clustered (Cartwright \& Harary, 1956). In general terms, two types of selection methods might separate clusters and subnetworks. In the first variant, the researcher or the research topic itself determines the rules of graph partitioning (MaOz, 2011). A researcher, for example, may partition the network of diplomatic missions based on geographical locations, political, economic or cultural similarities/differences. In this case, the selection method is flexible and depends on a subjective determination. In the second methodological alternative, the examination does not partition the nodes subjectively, rather attempts to identify the inbuilt clusters. Thus, the so-called cluster detection method determines network subgroups based on the frequency of links and cohesion of ties (Newman, 2010).

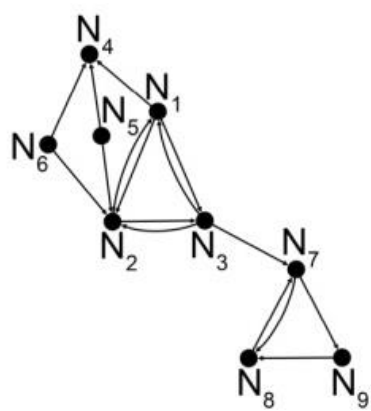

Figure 4. Example for a clique and structural equivalence in a directed network

Source: Edited by the author.

The discussion of cluster separation models also provides an opportunity to demonstrate types of cluster formations. Reflecting on the most typical types of cluster formations: two $\mathrm{N}$ nodes belong to the same subgroup if they form a cohesive subgroup or a similarity cluster. A cohesive subgroup is formed by a subset of vertices among whom ties are relatively robust, intense and frequent (Wassermann \& Faust, 1994). One of the most typical versions of cohesive subgroups is the clique which is a complete subgraph that produces high cohesion through reciprocated and directly connected ties. For example, to use the earlier model again, the diplomatic relations between Poland, Hungary and Czechia can be considered as a clique if $\mathrm{N}_{1}, \mathrm{~N}_{2}$ and $\mathrm{N}_{3}$ are mutually and directly connected (see Figure 4). While cohesive subgroups are detected through the frequency of ties, similarity clusters formed by comparable or identical properties of nodes (Hafner-Burton et al., 2009). Clustering based on similarity organizes the vertices due to level of sameness and equality of their network positions. Regular equivalence provides greater freedom in this sense, as this type of clustering identifies groups based on the similarities between $\mathrm{N}$ nodes and their direct neighbours (Newman, 2010). A much stricter formation is created by the selection method of structural equivalence. Two $\mathrm{N}$ nodes are structurally equivalent if they have identical connection links with the same $\mathrm{N}$ network nodes (Borgatti \& Grosser, 2015). For this reason, structural equivalence proposes a particularly rigorous selection alternative in international network analysis. For instance, in the case of the two reference networks, only the isolated components of the network from 1899 can be regarded as structurally equivalent nodes. To provide another example, in the model of Figure $4, \mathrm{~N}_{5}$ and $\mathrm{N}_{6}$ are also structurally equivalent actors as they both connected to $\mathrm{N}_{2}$ and $\mathrm{N}_{4}$ but have no other relations with any other $\mathrm{N}$ junctions.

Though distinct pieces of information might be gathered from the properties of individual nodes and subsets of junctions, we cannot draw comprehensive conclusions without knowing the attributes of the whole network. As in IR, understanding and connecting levels of analysis are also crucial in the network 
science, which, beyond the monadic, dyadic, triadic and subset groups, provides tools for examining systemic properties as well. In this case, the analysis of edge distribution is one of the most notable methodological options as it offers the opportunity to connect the systemic level with subgroups and individual units. Above all, network centrality is the most fundamental measurement of relational structure affecting multiple levels. The most commonly used option here is degree centrality. The model determines the centrality of $\mathrm{N}$ junctions based on the number of directly connecting $\mathrm{L}$ edges and compares this value to the degree number of other $\mathrm{N}$ nodes and the number of all relations in the network (Maoz, 2011). In the case of Figure 2, for instance, the United States has the highest number of degrees $\left(k_{U S A}=355\right)$. Consequently, the US has not only developed the highest number of direct connections but also maintains the highest influence in the network. As the sample displays a directed network, degree numbers in this case represent the sum of outdegrees (e.g. kUS $A^{\text {out }}=167$ ) and indegrees (e.g. $\left.k_{U S} A^{\text {in }}=188\right) .{ }^{8}$ The value of indegree also reflects on the prestige of examined nodes: the incoming links determine how frequently $\mathrm{N}$ actors pick other $\mathrm{N}$ junctions as a partner worth developing ties with (Rusinowska et al., 2011).

Besides degree centrality, there are various of other ways to measure the systemic position of nodes. Closeness centrality, for instance, is also based on the central role of nodes, though in this case, the centrality of $\mathrm{N}$ junction is determined by the paths and distances of edges (Newman, 2010). In other words, closeness centrality measures the shortest paths from one node to all other nodes. Another valuable option for IR is betweenness centrality which emphasizes the in-between role of nodes that serve as connection bridges. This model measures the importance of $\mathrm{N}$ junctions based on their ability to act as an intermediary, and it detects which junctions lie on the shortest paths among pairs of other nodes (Ibid.). As it seems, the betweenness centrality provides crucial data on the flow and control of information in a given network. ${ }^{9}$

The determination of centrality is crucial for many IR related topic as it makes possible to retrieve information about each individual actor, and it also identifies central, average and peripheral units of the network structure. It indicates, for example, if a given network topology is centralized, decentralized or distributed (Barabási, 2016). In case of a centralized network, one or only a few centres have the majority share of relations; in a decentralized topology, more centres share the most edges with about the same amount of links; while in the case of a distributed network, the number of relations and junctions is balanced. The topological characteristics also determine the bierarchical features of a given network, which is particularly useful in IR that often examines the causes of inequalities.

Last but not least, the formation and transformation of network connections may also reveal useful information content. As it was presented earlier, certain international actors tend to pick partners with high centrality (preferential attachment), while others establish partnerships based on similarity (bomophily) (MaOz, 2012a). The difference between these preferences could reveal how partnerships form and transform in international networks. While network science applies probability models to reveal patterns of preferences, partnership selections in the relatively less complex interstate networks could also be revealed by simple statistical methods (MaOz, 2012b).

Besides the above-mentioned alternatives, the network approach of IR offers several other opportunities that cannot be described here in detail. The application of these may be the consequence of examined research question or might be the result of deliberate interdisciplinarity. For instance, the investigation of information flow, the role of network effects, the possibility of scale-freeness or the relations between network systems are all possible topics requiring more sophisticated methodological alternatives.

\footnotetext{
${ }^{8}$ Degree centrality is calculated by the formula described in footnote 5 .

${ }^{9}$ The mathematical description of centralities is well beyond the scope of this paper. For a detailed description see Newman, 2010: 168-193.
} 


\section{DISCUSSION: POSSIBILITIES AND LIMITATIONS}

Methodological alternatives detailed above provide wide-scale opportunities for measurement and analysis, while also present non-traditional frameworks for executing primer and complex examination procedures. In the following pages the paper will examine the possibilities and limits of this promising research methodology. To complete this task, three categories or levels should be distinguished. At the first level, the network approach is considered as a tool of observation and visualization. At the second level, it is regarded as an innovative approach for understanding or re-evaluating problems of specific case studies. And finally, at the third and most complex level, it is viewed as a sophisticated instrument that may assist the redefinition of general theories and concepts.

To begin with the first level, it should be noted that nowadays the easily accessible network software and datamining technologies provide widescale opportunities for depicting international networks. While in the previous decades only a narrow circle, mostly state-based agencies and research groups, could afford to finance the depiction of large international networks, today modest prices allow ordinary students of IR to utilize modern network technologies. Although visual observation is widely underestimated in social sciences, data and network visualization can change these habits and may enable researchers to inspect virtual models of international relations. As in the case of other sciences, visual observation alone will not lead to major discoveries but may assist researchers in understanding the overall picture (Zinonyev, 2010).

At the second level, network approach may also prove beneficial in specific case studies in which the non-traditional toolkits of network analysis may lead to alternative results. However, it is questionable in which cases these non-traditional options can or should be applied. According to Borgatti et al. (2014), network research may display and analyse four basic types of dyadic phenomena: it may be used in cases of similarities, social relations, interactions and flows. In the case of similarities, shared attributes such as common memberships, physical locations or event participations (etc.) may be used for creating links. Network analysis is also able to outline various forms of social relations scaling from kinship relations (e.g. father and son) through role-based (e.g. teacher and student) and affective relations (e.g. like or dislike) to perceptual relations (e.g. knows something or not). While ties representing similarities and social relations outline static connections, interactions and flows display series of recurring events such as transactions, exchanges or their various forms of sequential continuity (Ibid.).

At this point, an additional comment should be made. It is rather obvious, but worth to mention that network approach may display and analyse both real and latent (abstract) relations. This duality is crucial for IR, as it often deals with material and non-material research subjects. On the one hand, the network approach may outline material relations such as exchange of diplomatic missions or trade of commodities. On the other hand, the methodology is also able to find connections between more abstract issues such as cognitive elements of foreign policy decision-making or the flow of norms and ideas.

In these topics and themes, the network approach may provide three options for analysis. First, it allows the researcher to analyse the structure of the examined system and describe its monadic, dyadic, triadic, clustered or systemic features. This method attempts to retrieve information mainly from the structure of the network, thus it applies the majority of methodological alternatives described above. The second alternative exceeds the level of topology and focuses on the dynamics of interactions taking place within the network. It examines the characteristics of processes in the relational system, their changes, reactions and the consequences of external inputs (Kramer, 2017). Last but not least, the third option considers the network. as a whole, as a subsystem of global relations, and attempts to understand how it influences international processes. In this regard, the network is considered as an individual international actor, a determinant factor of international relations that includes different entities, interactions, and processes between systemic attributes. 
The analysis of systemic macro processes also raises theoretical potentials: network studies of international relations may test and redefine general theories. Regarding the testing option, the methodology may reassess traditional beliefs of IR theories (Hafner-Burton et al. 2009). Although the network approach is not suitable for covering all areas of international studies, it may aid the understanding of several structural questions such as anarchy, balance of power, (inter)dependence, supply chain effects or international hierarchy. According to Maoz (2011), the network paradigm may be capable of even more progressive outcomes and could serve the redefinition of general theories. The author proposes a concrete example for such progressive possibilities and introduces the theory of Networked International Politics (NIP). The NIP theory, published in 2011, assumes that the international sphere can be interpreted as a complex system of interactions. In this system, interactions formed by „dyadic alignment and cross-network spillover effects" develop complex networks with both cooperative and conflictual properties (Ibid., p. 6). These sets of interrelated and interacting networks transform and determine the dynamics of international relations and influence the behaviour of nations (Ibid.). Consequently, one of the central elements of the theory is that the behaviour of network units is greatly influenced by network effects, which can be explored at the multiple levels of analysis and can be utilized in the process of theory formation.

Previous sections of the study described the potentials of network paradigm but also suggested that the methodology cannot be applied in all cases. The limitations of network approach can be perceived at multiple levels of applications, including observations, case studies, and theory-making. At the level of visual observation, network modelling struggles with the accelerated change of international interactions (Zinonyev, 2010). Although recent innovations in datamining allow network scientists to visualize large scale international subsystems, technologies still struggle to track real-time transformations. Consequently, contemporary network approaches always depict the past and allow to observe subsystems of international relations only at a certain period of time.

IR's network approach has limitations at the level of case studies too. Here, the methodology needs to be justified, as the incorrect or unnecessary application of network tools can lead to insignificant, misleading or false results. It is also essential to recognise the original purpose and definition of the method. As it was pointed out at the beginning of the paper, network science is the science of interactions. Consequently, it provides the most objective results when analysing actual relations. While the paradigm allows the depiction of latent connections, in these cases it is essential to demonstrate how abstract links affect the reality of international relations and why the application of network science is justified. Likewise, it is crucial to realise the decisive roles of data collectors and analysts. Majority of datasets provide aggregate information, and most analysts get their results based on selected and filtered data (Hafner-Burton et al., 2009). Although data purification procedures may still produce significant results, the impact and influence of researchers must be noted and acknowledged. Finally, it should be also recalled that network models of IR outline only specific subnetworks of international relations. This indicates that non-measured effects of disregarded subnetworks or the global network as a whole may influence and undermine the credibility of (partial) results.

Previous weaknesses also complicate the tasks of the theoretical level. In this case, theory testing seems to have more potentials than theory formation. While certain case studies may test and verify specific theoretical assumptions of IR, network science alone will not be suitable for "grand scale" theory formation. Indeed, international relations are about relations, but network approach still fails to explain crucial processes of IR. The method is perfectly capable of analysing how relations expand, networks grow or decline, but has little idea about how the first dyadic connection forms, why the last one disintegrates or how individual behaviour or irrationality affect the transformations of interactions. According to Borgatti et al. (2014), social network theory and analysis still needs considerable growth in research areas such as content, change or context, while dynamic interactions also deserve more attention. These deficiencies are 
supplemented with the assumption that IR can automatically apply theoretical propositions of other network disciplines. For instance, structural equivalence presupposes that similarity of network nodes will also mean similarity in the real world, while homophily connotes cooperation even though the actors with similar characteristics are often rivals of each other (Hafner-Burton et al., 2009). These shortcomings also characterise the application of imported toolkits which are often used without criticism. In fact, depictable subnetworks of IR are often smaller and simpler than their counterparts in natural sciences (MaOz, 2012b). Thus, the conventional network analysis of IR sometimes applies questionable methodology, uses less comprehensive measurement and, after all, obtains controversial data and results. All in all, although the network approach of IR is no longer exclusively descriptive, as Salancik claimed more than two decades ago (1995), it is still struggles to deliver sufficient theoretical generalisation of international relations.

\section{CONCLUSION}

The network paradigm of IR is one of the newest interdisciplinary branches of network science. It is based on the foundations of social network analysis, developed through several historical stages, and currently driven by technological innovations promoting more extensive use of the methodology. As in other disciplines, network approaches of IR also apply positivist examination and sticks to the mathematical measurement of quantifiable data. Sophisticated softwares today automatize most of these measurement procedures, however, critical use of digital network tools and interpretation of results remain manual responsibility of researchers.

Readers and practitioners of IR have formulated different views about the significance and role of network methodology. The author of this paper would argue that three main positions have emerged in the professional community of IR on the disciplinary use and utilization of network methodology. The first position considers network paradigm as a peripheral methodology borrowed from natural sciences. This perspective sees the method as an unconventional statistical tool for solving specific issues, a somewhat irregular mechanism that may help to supplement the results of traditional research procedures (Hwang, 2008). The second viewpoint attaches greater importance to the network approach, however, recognises the limits and weaknesses too. This position considers the network approach as an expanding methodological tool of IR that may receive greater importance in the future. Finally, there is also a third position, could be labelled as the branch of network idealists, which believes that network paradigm is much more than an auxiliary science of IR. According to this school, network science is the key for unfolding patterns of international interactions, and it is a swiftly developing field that may help to redefine or even re-establish general theories.

Without accepting any opinion, it can be stated that the network approach is gaining ground in the research of international relations. This slow expansion may continue in the future if further technological advances in datamining, data filtering, visualization and analysis automatization increase the efficiency of currently time-consuming research activities. Through technological innovations, network science may enable us to learn more about the nonlinear characteristics of international relations and allow researchers to explore global complexity. Newest experiments of the methodology already follow this path by studying challenges of the 21 st century. These experiments seek to understand rapid changes related to the fourth industrial revolution, the consequences of geographical or virtual interconnectivity, the physiology of commerce or the patterns of urban growth. These examples, however, also reveal the limits of network approach and suggest that IR will also preserve its traditional methodologies. Thus, despite some theoretical aspirations, the predicted advancement of so-called social physics will not yet materialize in IR, at least not with the overwhelming support of network science (Wendt, 2015; West, 2017). 


\section{ACKNOWLEDGEMENT}

This work was supported by the "EFOP-3.6.3-VEKOP-16-2017-00007 - Young researchers from talented students - Fostering scientific in higher education" programme.

\section{REFERENCES}

Axelrod, R. (1976). Structure of Decision: The Cognitive Maps of Political Elites. Princeton, New Jersey: Princeton University Press.

Barabási, A.-L. (2016). Network Science. Cambridge: Cambridge University Press.

Barabási, A.-L., \& Albert, R. (1999). Emergence of Scaling in Random Networks. Science, 286(5439), $509-512$. doi:10.1126/science.286.5439.509.

Barnes, J. (1954). Class and Committees in a Norwegian Island Parish. Human Relations, 7, 39-58. doi:10.1177/001872675400700102.

Bayer, R. (2006). Diplomatic Exchange Data set, v2006.1. Retrieved November 12, 2020, from http:/ / correlatesofwar.org. Borgatti, S. P., \& Grosser, T. J. (2015). Structural Equivalence: Meaning and Measures. In Wright, J. D., ed., International Encyclopedia of the Social \& Behavioral Sciences. Second Edition. Elsevier, 621-625. doi:10.1016/B978-0-08-0970868.43120-X.

Borgatti, S. P., Brass, D. J., \& Halgin, D. S. (2014). Social Network Research: Confusions, Criticisms, and Controversies. Contemporary Perspectives on Organizational Social Networks, 40. Bingley, UK: Emerald Group Publishing Limited, 1-29.

Brams, S. J. (1966). Transaction Flows in the International System. American Political Science Review, 60(4), 881-898. doi: $10.2307 / 1953763$.

Brams, S. (1969). The Structure of Influence Relationships in the International System. In Rosenau, J. N., ed., International Politics and Foreign Policy: A Reader in Research and Theory. New York: Free Press, 583-599.

Breiger, R. (1981). Structures of economic interdependence among nations. In Blau P. M. \&Merton, R. K., eds., Continuities in Structural Inquiry. London: Sage, 353-379.

Caporaso, J. A. (1978). Dependence, Dependency, and Power in the Global System: A Structural and Behavioral Analysis. International Organization, 32(1), 13-43. doi:10.1017/S0020818300003842.

Cartwright, D. \& Harary, F. (1956). Structural balance: a generalization of Heider's theory. Psychological Review, 63(5), 277-293. doi:10.1037/h0046049.

Christopherson, J. A. (1976). Structural Analysis of Transaction Systems: Vertical Fusion or Network Complexity? Journal of Conflict Resolution, 20(4), 637-662. doi:10.2307/173213.

Corbetta, R., \& Grant, K. A. (2012). Intervention in Conflicts from a Network Perspective. Conflict Management and Peace Science, 29(3), 314-340. doi:10.1177/0738894212443343.

Cranmer, S. J., Desmarais, B. A., \& Menninga, E. J. (2012). Complex Dependencies in the Alliance Network. Conflict Management and Peace Science, 29(3), 279-313. doi:10.1177/0738894212443446.

Dorussen, H., \& Ward, H. (2008). Intergovernmental Organizations and the Kantian Peace: A Network Perspective. Journal of Conflict Resolution, 52(2), 189-212. doi:10.1177/0022002707313688.

Eulau, H. (1962). Bases of Authority in Legislative Bodies: A Comparative Analysis. Administrative Science Quarterly, 7(3), 309-321.

Europa Publications (2016). The Europa World Year Book. 57th edition. London: Routledge.

Faber, J. (1987). Measuring Cooperation, Conflict, and the Social Network of Nations. Journal of Conflict Resolution, 31(3), 438-464. doi:10.1177/0022002787031003003.

Fiellin, A. (1962). The Functions of Informal Groups in Legislative Institutions. The Journal of Politics, 24(1), 72-91. doi: $10.2307 / 2126738$.

Hafner-Burton, E., \& Montgomery, A. H. (2006). Power Positions: International Organizations, Social Networks, and Conflict. Journal of Conflict Resolution, 50(1), 3-27. doi:10.1177/0022002705281669.

Hafner-Burton, E. Kahler, M., \& Montgomery, A. H. (2009). Network Analysis for International Relations. International Organization, 63(3), 559-592. doi:10.1017/S0020818309090195. 
Healy, B., \& Stein, A., (1973). The Balance of Power in International History: Theory and Reality. Journal of Conflict Resolution, 17(1), 33-61. doi:10.1177/002200277301700103.

Heider F. (1946). Attitudes and Cognitive Organization. The Journal of Psychology, 21, $107-112$. doi:10.1080/00223980.1946.9917275.

Hoff, P. D. \& Ward, M. D., (2004). Modeling Dependencies in International Relations Networks. Political Analysis, 12(2), 160-175. doi:10.1093/pan/mph012.

Hwang, S. (2008). Past, present, and future of social network analysis: Network as a metaphor,

method, theory, or paradigm? International Journal of Interdisciplinary Social Sciences, 4(9), 21-36. doi:10.18848/18331882/CGP/v04i09/52979.

Kim, R. E. (2020). Is Global Governance Fragmented, Polycentric, or Complex? The State of the Art of the Network Approach. International Studies Review, 22(4), 903-931. doi:10.1093/isr/viz052.

Kramer, C. R. (2017). Network Theory and Violent Conflicts Studies in Afghanistan and Lebanon. London-New York: Palgrave Macmillan.

Lazarsfeld, P. F., Berelson, B. R. \& McPhee, W. N. (1968). Voting: A Study of Opinion Formation in a Presidential Campaign. Chicago: University of Chicago Press.

Maoz, Z. (2011). Networks of Nations: The Evolution, Structure, and Impact of International Networks, 1816-2001. CambridgeNew York: Cambridge University Press. doi:10.1017/CBO9780511762659.

Maoz, Z. (2012a). How Network Analysis Can Inform the Study of International Relations. Conflict Management and Peace Science, 29(3), 247-256. doi:10.1177/0738894212443341.

Maoz, Z. (2012b). Preferential Attachment, Homophily, and the Structure of International Networks, 1816-2003. Conflict Management and Peace Science, 29(3), 341-369. doi:10.1177/0738894212443344.

Maoz, Z. (2017). Network Science and International Relations. Oxford Research Encyclopedia of Politics. Oxford: Oxford University Press. doi:10.1093/acrefore/9780190228637.013.517.

Maoz, Z., Kuperman, R. D., Terris, L. \& Talmud, I. (2006). Structural Equivalence and International Conflict - A Social Networks Analysis. Journal of Conflict Resolution, 50(5), 664-689. doi:10.1177/0022002706291053.

Matthews, D. R. (1959). The Folkways of the United States Senate: Conformity to Group Norms and Legislative Effectiveness. American Political Science Review, 53(4), 1064-1089. doi:10.2307/1952075.

McDonald, H. B. \& Rosecrance, R. (1985). Alliance and Structural Balance in the International System: A Reinterpretation. Journal of Conflict Resolution, 29(1), 57-82. doi:10.1177/0022002785029001004.

Mitchell, J. C. (1969). Social Networks in Urban Situations: Analyses of Personal Relationships in Central African Towns. Manchester: Manchester University Press. doi:10.1086/225354.

Monsma, S. V. (1966). Interpersonal Relations in the Legislative System: A Study of the 1964 Michigan House of Representatives. Midwest Journal of Political Science, 10(3), 350-363. doi: 10.2307/2108890.

Moreno, J. L. (1934). Who shall survive? A new approach to the problem of human interrelations. Nervous and mental disease monograph series, No 58. Nervous and Mental Disease Publishing Co.

Nemeth, R. J. \& Smith, D. A. (1985). International Trade and World-System Structure: A Multiple Network Analysis. Fernand Braudel Center Review, 8(4), 517-560.

Newman, M. E. J. (2010). Networks: An Introduction. New York: Oxford University Press. doi:10.1093/acprof:oso/9780199206650.001.0001.

Patterson, C. H. (1959). Attitudes Toward Work. Vocational Guidance Quarterly, 7(3), 155-158.

Polacheck, S. (1980). Conflict and Trade. Journal of Conflict Resolution, 24(1), 55-78. doi:10.1177/002200278002400103.

Routt, G. C. (1938). Interpersonal relationships and the legislative process. The Annals of the American Academy of Political and Social Science, 195(1), 129-136. doi:10.1177/000271623819500118.

Rusinowska A., Berghammer R., De Swart H., \& Grabisch M. (2011). Social Networks: Prestige, Centrality, and Influence. In: de Swart H., eds., Relational and Algebraic Methods in Computer Science. RAMICS 2011. Lecture Notes in Computer Science, vol 6663. Berlin-Heidelberg: Springer, 22-39. doi:10.1007/978-3-642-21070-9-2.

Russett, B. M., \& Lamb, C. W. (1969). Global patterns of diplomatic exchange 1963-1964. Journal of Peace Research, 6(1), 37-55. doi:10.1177/002234336900600104.

Russett, B. M. (1968). Delineating international regions. In: Singer, D. J., ed., Quantitative International Politics: Insights and Evidence, New York: Free Press, 317-352. 
Salancik, G. R. (1995). Wanted: A good network theory of organization. Administrative

Science Quarterly, 40, 345-349. doi:10.2307/2393642.

Scott, J. (2000). Social Network Analysis: A Handbook. London-New Delhi: SAGE Publication. doi:10.4135/9781529716597.

Shannon, Paul et al. (2003). Cytoscape: a software environment for integrated models of biomolecular interaction networks. Genome Research, 13(11): 2498-2504. doi:10.1101/gr.1239303.

Steiber, S. (1979). The World System and World Trade: An Empirical Exploration of Conceptual Conflict. Sociological Quarterly, 20(1): 23-36. doi:10.1111/j.1533-8525.1979.tb02182.x.

Szántó, Z. (2011). Egy kettős évforduló kapcsán: a strukturális kiegyensúlyozottságelméletének újrafelfedezése [Regarding a dual anniversary: re-discovering the theory of structural equivalence]. In: Takács, K., ed., Társadalmi kapcsolathálózatok elemzése [Analysis of social networks]. Budapest: BCE Szociológia ésTársadalompolitika Intézet, 32-38.

Victor, J. N., Montgomery, A. H., \& Lubell, M. (2017). The Oxford Handbook of Political Networks. Oxford: Oxford University Press. doi:10.1093/oxfordhb/9780190228217.001.0001.

Wasserman, S. \& Faust, K. (1994). Social Network Analysis: Methods and Applications. Cambridge: Cambridge University Press. doi:10.1017/CBO9780511815478.

Wendt, A. (2015). Quantum Mind and Social Science: Unifying Physical and Social Ontology. Cambridge: Cambridge University Press. doi:10.1017/CBO9781316005163.

Wertheimer, M., \& Puente, A. E. (2020). A Brief History of Psychology. Sixth Edition. New York-London: Routledge. doi:10.4324/9780203686485.

West, G. (2017). Scale: The Universal Law of Growth, Innovation, Sustainability, and the Pace of Life, in Organisms, Cities, Economies, and Companies. New York: Penguin Press.

White, H. C., Boorman, S. A., \& Breiger, R. R. (1976). Social Structure from Multiple Networks I. Blockmodels of Roles and Positions. American Journal of Sociology, 81(4),730-780. doi:10.1086/226141.

Zinonyev, A. (2010). Data visualization in political and social sciences. Cornell University, Retrieved November 10, 2020, from http://arxiv.org/pdf/1008.1188v1.pdf. 